\title{
Extreme storm surges: a comparative study of frequency analysis approaches
}

\author{
Y. Hamdi ${ }^{1,2}$, L. Bardet ${ }^{1}$, C.-M. Duluc ${ }^{1}$, and V. Rebour ${ }^{1}$ \\ ${ }^{1}$ Institute for Radiological Protection and Nuclear Safety, BP17, 92262 Fontenay aux Roses CEDEX, France \\ ${ }^{2}$ National Engineering School of Gabes, University of Gabes, Rue Omar Ibn-Elkhattab 6029, Gabès, Tunisia \\ Correspondence to: Y. Hamdi (yasser.hamdi@irsn.fr)
}

Received: 30 September 2013 - Published in Nat. Hazards Earth Syst. Sci. Discuss.: 19 November 2013

Revised: 13 May 2014 - Accepted: 14 May 2014 - Published: 13 August 2014

\begin{abstract}
In France, nuclear facilities were designed around very low probabilities of failure. Nevertheless, some extreme climatic events have given rise to exceptional observed surges (outliers) much larger than other observations, and have clearly illustrated the potential to underestimate the extreme water levels calculated with the current statistical methods. The objective of the present work is to conduct a comparative study of three approaches to extreme value analysis, including the annual maxima (AM), the peaks-overthreshold (POT) and the $r$-largest order statistics ( $r$-LOS). These methods are illustrated in a real analysis case study. All data sets were screened for outliers. Non-parametric tests for randomness, homogeneity and stationarity of time series were used. The shape and scale parameter stability plots, the mean excess residual life plot and the stability of the standard errors of return levels were used to select optimal thresholds and $r$ values for the POT and $r$-LOS method, respectively. The comparison of methods was based on (i) the uncertainty degrees, (ii) the adequacy criteria and tests, and (iii) the visual inspection. It was found that the $r$-LOS and POT methods have reduced the uncertainty on the distribution parameters and return level estimates and have systematically shown values of the 100 and 500-year return levels smaller than those estimated with the AM method. Results have also shown that none of the compared methods has allowed a good fit at the right tail of the distribution in the presence of outliers. As a perspective, the use of historical information was proposed in order to increase the representativeness of outliers in data sets. Findings are of practical relevance, not only to nuclear energy operators in France, for applications in storm surge hazard analysis and flood management, but also for the optimal planning and design of fa-
\end{abstract}

cilities to withstand extreme environmental conditions, with an appropriate level of risk.

\section{Introduction}

Nuclear power is the primary source of electricity in France and it is operated by Electricité de France (EDF). Nuclear power facilities have to be designed to withstand extreme environmental conditions. The majority of nuclear facilities in France are located away from the coasts and obtain their cooling water from rivers. Five plants are located on the Atlantic French coast: Blayais, Gravelines, Penly, Paluel, and Flamanville. Generally, safety and design rules stipulate that protection structures should be designed to exceed specific levels of reliability. This requires specification of values of design variables with very low probabilities of exceedance (considering, for instance, a 1000-year return surge). The storm surge is a random environmental component which is fundamental input to conduct a statistical investigation for the submersion hazard (e.g., Bernier and Thompson, 2006; Von Storch et al., 2008; Bardet et al., 2011; Bernardara et al., 2011; Irish et al., 2011; Northrop and Jonathan, 2011).

During the last two decades, France has experienced several violent climatic events, such as the storm of 1987, Martin (1999), Klaus (2009), and Xynthia (2010) that induced significantly high storm surges, appearing as outliers in the series of observations. In addition, the extreme event that partially flooded the Blayais nuclear power plant in 1999 (storm Martin) was caused when a combination of a high tide, an outlier surge and high waves induced by strong winds led to the overflow of the dikes of the Blayais site, which were 
not designed for such a combination of events (Mattéi et al., 2001). Therefore a guide of protection including fundamental changes to the evaluation of flood hazard at nuclear power plants has been recently published by the Nuclear Safety Authority (ASN, 2013). However, some issues like the frequency estimation of extreme surges remain among the priorities of the Institute for Radiological Protection and Nuclear Safety (IRSN).

Statistical modeling is essential for the estimation of such extreme events occurrence. Relating extreme events to their frequency of occurrence using probability distributions has been a common issue since the 1950s (e.g., Chow, 1953; Dalrymple, 1960; Gringorten, 1963; Cunnane, 1978; Cunnane and Singh, 1987; Chow et al., 1988; Rao and Hamed, 2000). The frequency estimation corresponding to long return periods is based on the extreme value theory (Coles, 2001).

The AM (annual maxima) method is a simple and straightforward approach, adopted by many national design codes worldwide, in which a generalized extreme value (GEV) distribution is used to fit annual maximum observations. It uses data separated into blocks of 1 year and from these blocks only the maximum is used. However, the statistical extrapolation, to estimate storm surges corresponding to high return periods, is seriously contaminated by sampling and model uncertainty if data are incomplete and/or available for a relatively limited period. Another major disadvantage of the AM is that if we only extract the annual maximum observation, we will lose lots of high sea water levels occurring during the whole year. This has motivated the development of approaches to enlarge the sample extreme values beyond the annual maxima. A way around this is to use a point process method (PPM) by setting an exceedance high threshold above which observations are taken as extremes (POT approach) or by extracting a fixed number of high observations in each year ( $r$-LOS approach). This way will allow us to use much more of the data collected during the year.

The POT (peaks-over-threshold) and the $r$-LOS ( $r$-largest order statistics) approaches are two particular cases of the PPM. The PPM is commonly considered as an alternative to the AM method. The POT approach models the peaks exceeding a sufficiently high threshold. The generalized Pareto distribution (GPD) is the most adapted theoretical distribution to fit POT series. In addition, the threshold leads to a sample with data which are more representative of extreme events. However, it is difficult to choose a threshold level and this makes for subjectivity in what should be taken as a reasonable threshold. The use of a too-low threshold introduces automatically a bias in the estimation by using observations which may not be extreme data and this violates the principle of the extreme value theory. On the other hand, the use of a too-high threshold will reduce the sample of extreme data. It was also shown in the literature that the POT approach cannot easily be used in presence of temporal and spatial variability, because a separate threshold must be selected for each year and site (Butler et al., 2007). The $r$-LOS model is similar to the AM except that, instead of recording only maximum observations for each block, the $r$ largest ones are recorded (the case with $r=1$ is equivalent to the AM approach). The function density for the $r$-LOS model is slightly different from the AM density, but it can be approximated to the AM model, considering that each $r$ value is the maximum observation of a fictitious year. The $r$-LOS model is considered by many authors as an alternative to the more usual AM and POT methods (Smith, 1986; An and Pandey, 2007; Butler et al., 2007). The advantage of using a PPM method is that we can include more recorded observations into the estimation of the distribution function parameters and thus with more data we will decrease the estimation variance and be more confident about our parameter estimates. The reader is referred to Coles (2001) for more details about AM and the PPM methods presented above.

As it has been outlined with the storms of 1987, 1999 or 2010, data sets may contain outliers. Traditionally, an outlier is defined as an observation point that departs significantly from the trend of the remaining observations when displayed as an experimental probability scatter plot. Consequently, outliers interfere with the fitting of simple trend curves to the data and, unless properly accounted for, are likely to cause simple fitted trend curves to grossly misrepresent the data. It was shown in the literature that the methods outlined above (MA and PPM) are not always adapted to data sets containing outliers (e.g., Stedinger, 1988). In an earlier study to overcome the shortcoming of short data series and the outlier issue, Bardet et al. (2011) and Bernardara et al. (2011) assessed POT series of storm surges in a regional frequency analysis framework. In a regional context and in comparison with local analyses, observed exceptional surges become normal extreme values and do not appear to be outliers any more. However, the regional frequency analyses, in particular the inter-site dependency issue, need to be improved (Bardet et al., 2011).

The basic reason for the work presented in this paper arises from the fact that statistical characterization of high sea water levels, in the French Atlantic coasts, using and comparing several approaches, has been rarely addressed in the literature despite their significant impacts not only on nuclear related facilities, but also on social and economic activities. The treatment, in a local frequency analysis context, of outliers present in storm surge data sets is also very limited in the literature. This work is a study of research for which some hypotheses have been taken to allow a comparison of the different approaches. In particular, the MA, POT or $r$-LOS samples of data have been built considering the same years of observations for one site, even if other POT data were available for instance. Therefore some of the hypotheses taken for this work may be modified in the framework of specific design studies, depending on the aims which are required, as the criteria for the selection of the POT threshold or for the fitting adequacy. 
A brief review of the theoretical background of the extreme value frequency analysis is presented in Sect. 2 of this paper. The AM, $r$-LOS, and POT methods applied to storm surges data collected at 21 sites in the French Atlantic coast are presented in Sect. 3, with a verification of the frequency analysis assumptions. Section 4 summarizes the discussion as well as a comparison of the AM, $r$-LOS and POT approaches. Further discussions on using historical information to improve the frequency estimation of extreme surges are presented in Sect. 5, before the conclusion and perspectives in Sect. 6.

\section{Extreme value frequency estimation}

Regardless of the analysis method, a standard frequency estimation procedure includes the following steps: (i) verification of randomness, homogeneity and stationarity hypotheses and detection of outliers; (ii) computation of empirical probabilities of exceedance using sorted and ranked observations; (iii) fitting a curve to these observations with distribution functions, parameters estimation and applying adequacy criteria and tests to select the more appropriate method and the best distribution to represent the data; (iv) extrapolating or interpolating so that the return period $T$ of the extreme value of interest (say 100 years) is estimated.

\subsection{Hypotheses and statistical tests}

Randomness, homogeneity and stationarity of time series are necessary conditions to conduct a frequency analysis (Rao and Hamed, 2001). Three non-parametric tests were used: the Wald-Wolfowitz test (WWT) for randomness (Wald and Wolfowitz, 1943), the Wilcoxon test (WT) for homogeneity (Wilcoxon, 1945) and the Kendall test (KT) for stationarity (Mann, 1945). Another important test but not required to conduct a frequency analysis is the Grubbs-Beck test (GBT) for the detection of outliers (Grubbs and Beck, 1972).

\subsection{Frequency estimation}

Several formulas exist to calculate the empirical probability of an event. On the basis of different statistical criteria it is found in several studies (e.g., Alam and Matin, 2005; Makkonen, 2006) that the Weibull plotting position formula $p_{\mathrm{e}}=m /(N+1)$ directly follows from the definition of the return period ( $m$ is the rank order of the ordered surges magnitudes and $N$ is the record length). It was also shown that this formula (Weibull, 1939) predicts much shorter return periods of extreme events than the other commonly used methods. The Weibull plotting position was then used in the present work.

Of the many statistical distributions commonly used for extremes, the GEV function was retained for the AM and $r$ LOS methods and the GPD function was used to apply the POT approach.
The GEV distribution introduced by Jenkinson (1955) is the limiting distribution for the maximum (and the minimum) of i.i.d. (independent and identically distributed) random variables. It combines three asymptotic extreme value distributions, identified by Fisher and Tippet (1928), into a single form with the following cumulative distribution function $F$ :

$F(x)=\left\{\begin{array}{ll}e^{-\left(1+\xi \frac{x-\mu}{\sigma}\right)^{-1 / \xi}} & \xi \neq 0 \\ e^{-e^{-(x-\mu)} / \sigma} & \xi=0\end{array}\right.$,

where $\mu, \sigma>0$, and $\xi$ are the location, scale, and shape parameters, respectively. The parameterization for the shape parameter $\xi$ in Eq. (1) follows the notational convention prevalent today in the statistics literature; for example, in the hydrologic literature, it is still common to parameterize in terms of $\xi^{*}=-\xi$ instead.

Depending on the value of the shape parameter $\xi$, the GEV can take the form of the Gumbel, Fréchet or Negative Weibull distributions. When $\xi=0$, it is the Type I GEV (Gumbel) distribution which has an exponential tail. When $\xi>0$, the GEV becomes the Type II (Fréchet) distribution. In the third case, when $\xi<0$, it is the Type III GEV (the reverse Weibull function). The last one has a finite and short theoretical upper tail $(\infty<x<\mu-\sigma / \xi)$ that may be useful for estimates of specific cases of extreme values such as surges, which may have an upper bound. The heavy upper tail in the first case with the Fréchet distribution is unbounded $(\mu-\sigma / \xi<x<\infty)$ and allows for relatively high probability of extreme values. Generally when examining extreme storm surge events we are interested in asking the question: How often do we expect a region to be submerged by sea water? And if it is submerged how high will the surge be? To answer this question, we need to calculate the $T$ years return level. The $1 / p$ return level $\hat{z}_{p}$ (computed from the GEV distribution) is the quantile of probability $(1-p)$ to exceed $\hat{z}_{p}$ and it is given by

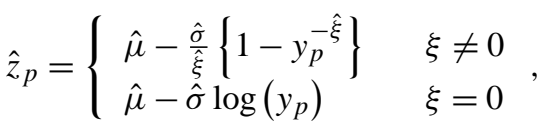

where $y_{p}=-\log (1-p)$ and $\hat{\mu}, \hat{\sigma}$ and $\hat{\xi}$ are the GEV distribution parameters estimated with the maximum likelihood method.

On the other hand, as mentioned earlier, a GP distribution calculates probabilities of observing extreme events which are above a sufficiently high threshold. Given a threshold $u$, the distribution of excess values of $x$ over $u$ is defined by

$F_{u}(y)=\operatorname{Pr}\{X-u \leq x \mid X>u\}=\frac{F(x)-F(u)}{1-F(u)}$,

which represents the probability that $X$ exceeds $u$ by at most an amount $y$, where $y=x-u$. Several studies show that, 
when the selected threshold $u$ is sufficiently high, the asymptotic form of the distribution function of excess $F_{u}(y)$ converges to a GP function (e.g., Pickands, 1975) which has the following cumulative distribution function:

$$
G(x)=\left\{\begin{array}{ll}
1-(1+\xi x / \sigma)^{-\frac{1}{\xi}} & \xi \neq 0 \\
1-e^{-x / \sigma} & \xi=0
\end{array} .\right.
$$

The GP distribution corresponds to a (shifted) exponential distribution with a medium-size tail when $\xi=0$, and to a long-tailed (and unbounded) ordinary Pareto distribution for positive values of $\xi$ and finally, when $\xi<0$, it takes the form of a Pareto Type II distribution with a short tail upper bounded by $\mu+\sigma / \xi$.

Several methods exist to estimate distribution parameters. Although for most of the distribution functions, the maximum likelihood method is considered in many investigations as an excellent option for parameter estimation, it has been shown that the method of moments is more effective (Ashkar and Ouarda, 1996) when using the GPD. For both the GEV and the GP distributions, the parameters were estimated in the present work with the maximum likelihood method.

\subsection{Adequacy criteria and tests}

Questions like the adequacy in the statistical analysis and goodness-of-fit (GOF) tests should be addressed when comparing different distributions and methods. Many GOF tests studies were conducted in the literature. Steele and Chaseling (2006) have shown that no single test statistic can be recommended as the "best" and we need to consider carefully the choice of a test statistic to optimize the power of our test of goodness of fit. Conventional measures of the adequacy of a specified distribution and to compare and select the more appropriate method is to compute the BIAS and RMSE (root mean squared error). The RMSE, also known as the fit standard error, is the square root of the variance of the residuals. It indicates the absolute fit of the model to the data and how close the observed probabilities are to those of the model. As the square root of a variance, RMSE can be interpreted as the standard deviation of the unexplained variance, and has the useful property of being in the same units as the response variable. Lower values of RMSE indicate better fit. RMSE is a good measure of how accurately the model predicts a response. The Akaike and the Bayesian information criteria are two other selection criteria based on the likelihood function and involving the number of parameters and the sample size. Since the methods that we compare in the present paper produce data sets of different lengths and use the same distribution function, our comparative study will be biased if we use these two last criteria (because they are based on the sample size).

In addition to these criteria, many adequacy statistics and goodness-of-fit tests, such as the Chi-2, the KolmogorovSmirnov (KS) and the Anderson-Darling (AD), can also be used to discriminate between distributions and/or methods. The Chi-2 test can be used to verify the hypothesis about the parent distribution of the sample. The advantage of this test is that one can be certain that a fit is not adequate if this test fails for a distribution. On the other hand, this test has the shortcoming of being considered, by the scientific community, not very powerful. Moreover, we strongly believe that using the Chi-2 for continuous distributions is a bad idea (the test result depends strongly on the choice of the classes far more than the values of the sample). The AD test (Stephens, 1974 ) is used to test if a sample came from a population with a specific distribution. It is an improved version of the KS test and gives more weight to the distribution tails than do the KS and the Chi- 2 tests. Contrarily to the AD test, with the KS test the critical values do not depend on the specific distribution being tested. The AD test makes use of the specific distribution in calculating critical values and it is not distribution free. The $\mathrm{AD}$ test is then considered in the present paper as an alternative to the KS and Chi-2 GOF tests.

\section{Study area and extraction of extreme events}

Data used in this study are taken from tide gauges located on the French Atlantic coast. A sea water level database was provided by the French Oceanographic Service SHOM (Service Hydrographique et Océanographique de la Marine). It was shown that the mean observed tide levels in the French Atlantic coast increase with time and mean predicted ones are constant (Bardet et al., 2012). To compare the observed and predicted sea level data, observations at each site have been corrected so that sea level rise did not affect the average annual observed levels skew. Storm surge time series were extracted from these predicted and observed tide levels. The reader is referred here to Bardet et al. (2012). The selected peaks for a particular year have to be selected from distinct and statistically independent storm surge events. Several algorithms that deal with the independence of events are presented in the literature (e.g., Tawn, 1988; Butler et al., 2007). To reduce mutual dependence in data sets, and according to the procedure described by Bardet at al. (2012), time series of 3-day independent observations of skew surges were created for 21 sites located on the French Atlantic coast. Figure 1 displays the geographic distribution of the stations in the French Atlantic coast. These tide gauges provide good spatial coverage and represent different climate regions from the northeastern to southeastern coast. It should be noted here that in this study we used the same sites analyzed by Bardet and Duluc (2012), but not the same periods of data. Indeed, Bardet and Duluc (2012) used only the POT method and therefore they were able to use all the data at their disposal. In our case, our goal is to compare the methods and the same raw series should be used for each method. The use of the POT method in our case study is limited by this constraint (the complete 
time series have not been exploited) which may have a negative impact on the performance of the method.

The record length was the main criterion to select the stations. The AM approach was applied to sufficiently long data sets (e.g., Dunkerque, Le Conquet, Brest). We also included sites with 14 to 25-year data sets (St-Nazaire, Olonne, La Rochelle, Port Bloc) to examine the contribution of PP approaches (POT and $r$-LOS) expanding relatively short series. Within this selected subset, some stations were lacking data for relatively long periods. In some cases, these missing periods can reach several months and may occur during the season of high surges (autumn and winter). This may limit the performance of AM and $r$-LOS frequency analysis methods. Using these criteria, a first selection was done on the annual maximum data sets. Saint-Malo, Concarneau, Le Crouesty, and Arcachon stations were removed because they have very small record lengths. Within the selected subset of AM observations, the minimum length of record is 14 years ( $\mathrm{La}$ Rochelle) and the maximum is 56 years for Brest tide gauge. Figure 1 shows record lengths of the retained sites.

\subsection{Extraction of extreme events using the $r$-LOS and POT models}

Similarly to the AM data sets, POT, and $r$-LOS observations were extracted from the same time series. The extraction of these data sets requires caution regarding base surges or thresholds $u$ (for the POT approach) and $r$ (for the $r$-LOS approach) values to be used. There is a bias-variance tradeoff associated with these parameters. A large value of $u$ or a small value of $r$ can result in large variance, but the opposite is likely to cause a bias and violate the assumption of the Poisson process generating the extreme values (Smith, 1986). One of the criteria used to select $u$ or $r$ is that they minimize the variance associated with a required quantile estimate. Coles (2001) has shown that stability plots constitute a graphical tool for selecting optimal value of $u$ or $r$. The stability plots are the estimates of the GPD parameters and the mean residual life-plot as function of $u$ when using the POT approach, and the standard errors of the GEV shape parameter and the $T$ years return levels as function of $r$ in the $r$-LOS case. The value should be extracted from the linear part of the curve. To avoid violating the assumption of the Poisson process generating the extreme values, the required threshold should be as high as possible and the required value of $r$ should be as low as possible (without considerably increasing the variance). This is why in seeking the stability zones we begin exploring the POT diagnostic plots from the right ( $u$ should be as high as possible) and the $r$-LOS ones from the left ( $r$ should be as low as possible). At the same time, to minimize the variance, the smallest value of the identified stable part is commonly considered by the scientific community as an optimal choice of $u$ or $r$. It is important to note that depending on the objectives of the study, another value can be selected as long as it remains in the stable part of the curve. The table presented in Fig. 1 shows the optimal values of $r$ and $u$ for each considered site.

In the $r$-LOS model, a data set was extracted for each site from the raw data and the analysis was repeated for $r=1-10$ (if $r=1$ then this simplifies to the AM method). The three GEV parameters and associated standard errors were calculated. As an example, the standard errors corresponding to the shape parameter and associated with 100 and 500-year surges for the Brest (56-year data set) and Boulogne (20year data set) sites are shown in Fig. 2. We can clearly see a decrease of the variability with an increase in $r$ up to 3 for Brest and up to 5 for Boulogne, but there is no appreciable change in the standard error for $r$ greater than these values. Therefore, an optimum choice of $r$ is expected to be close to 3 for Brest and 5 for Boulogne. As it will be presented later, the values of $r$ presented in Fig. 1 are sufficient to provide minimum variance quantile estimates. These values are similar to those recommended by several authors (e.g., Tawn, 1988; Guedes Soares and Scotto, 2004), who concluded that results of the $r$-LOS method for $r=3-7$ are very stable and consistent.

In the POT model, a data set was also extracted for each site from the raw data and the analysis was repeated for $u=20-80 \mathrm{~cm}$. To determine the required threshold, diagnostic plots which plot the GPD shape and modified scale parameters and also the mean residual life plot over a range of threshold values were used. Figure 3 shows the mean residual life plot for the Calais and Dieppe surge data sets. Interpretation of a mean residual life plot is not always simple in practice. The idea is to find the lowest threshold where the plot is nearly linear and appears as a straight line for higher values, taking into account the $95 \%$ confidence limits. For the Calais site, the graph appears to curve from $u=20 \mathrm{~cm}$ to $u=46 \mathrm{~cm}$, beyond which it is nearly linear until $u=80 \mathrm{~cm}$. It is tempting to conclude that there is no stability until $u=46 \mathrm{~cm}$, after which there is approximate linearity. This suggests we take $u=46 \mathrm{~cm}$. There are 84 exceedances of this threshold, enough to make meaningful inferences. By the same reasoning for the Dieppe data set, we can see that the plot appears roughly linear from about $u \approx 52 \mathrm{~cm}$ to $u \approx 65 \mathrm{~cm}$ and is erratic above $65 \mathrm{~cm}$, so we selected $52 \mathrm{~cm}$ as a plausible choice of threshold and there are 75 exceedances of this threshold.

The second procedure for threshold selection is to estimate the model at a range of thresholds. Above a level $u$ at which the asymptotic motivation for the GPD is valid, estimates of the shape parameter should be approximately constant, while estimates of the modified scale parameter should be linear in $u$. The reader is referred to Coles (2001) for more details about modeling threshold excesses and threshold selection. We can draw the same conclusions with respect to the threshold value (for Calais and Dieppe sites) by inspecting the GPD modified scale and shape parameters plots presented in Fig. 3. The number of surge events $N_{u}$ is, as expected, greater than the number of years of records $N$ (Fig. 1). The American 


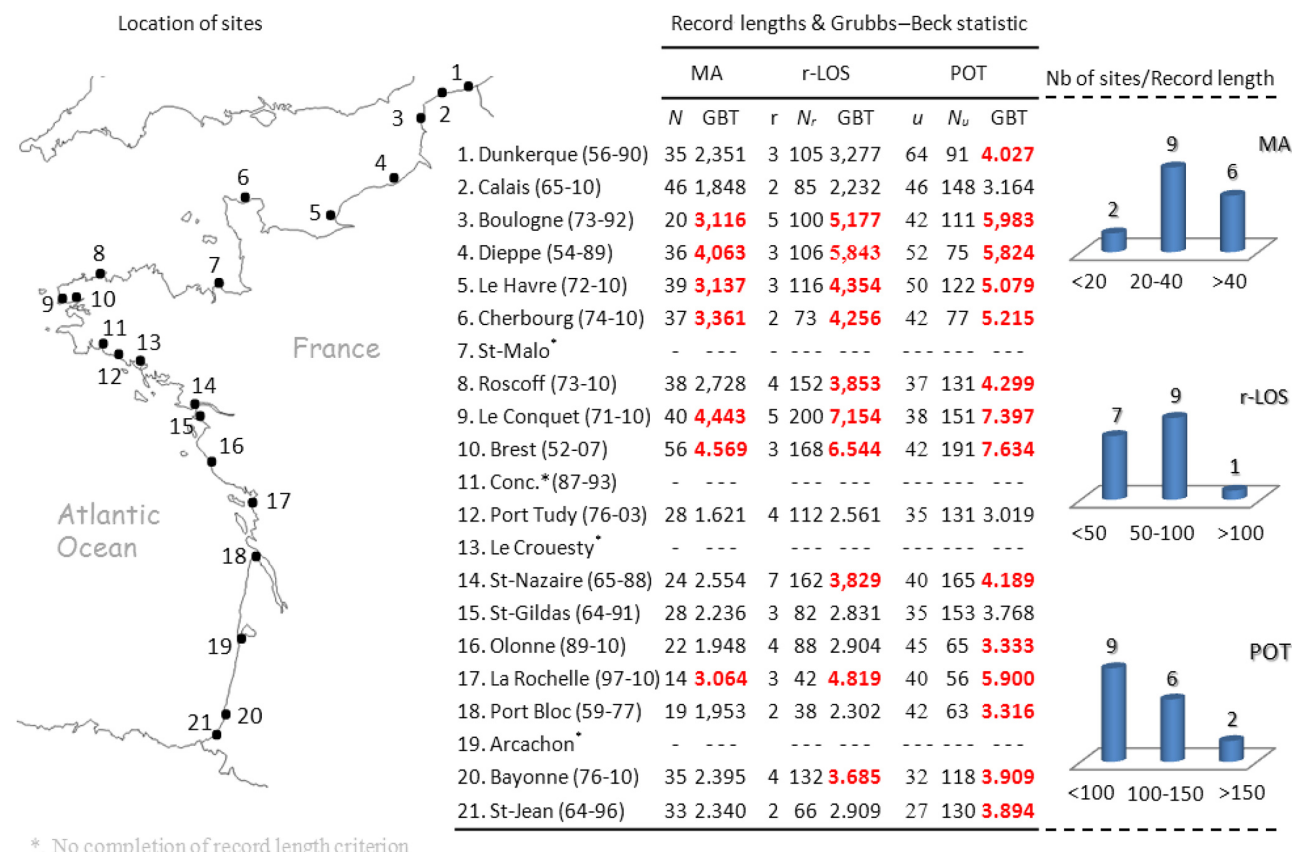

Figure 1. To the left: location of sites. In the middle: a table containing the site names and periods of records, the record lengths and the Grubbs-Beck statistic (GBT) of each site and for the annual maxima (AM), the peaks-over-threshold (POT) and the $r$-largest order statistics ( $r$-LOS) methods. The $r$ (the $r$-largest observations) and $u$ (threshold $-\mathrm{cm}$ ) values are also presented in this table. To the right: distribution of record lengths.
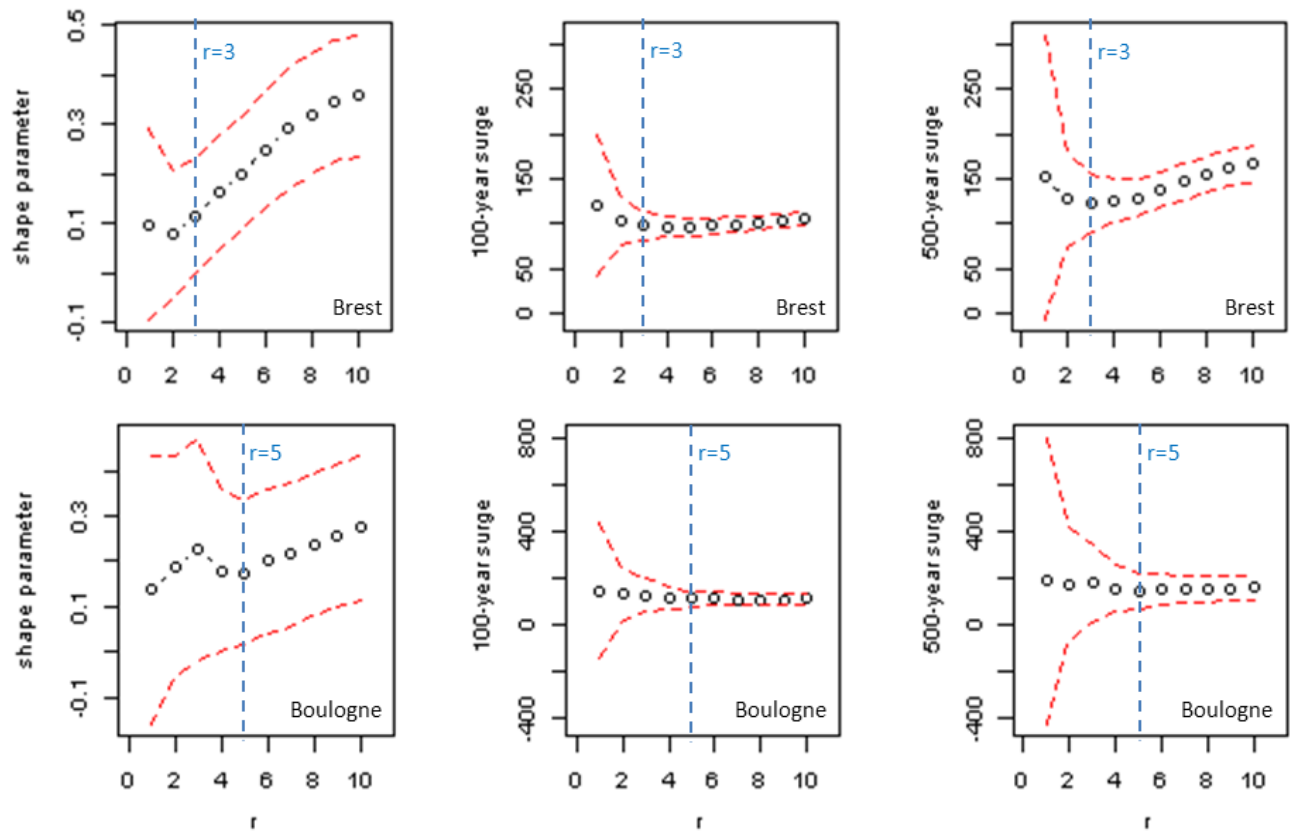

Figure 2. Estimation of $r$ (the $r$-largest observations): the GEV shape parameter and 100 and 500 -year storm surges (cm) with $95 \%$ confidence intervals (Brest and Boulogne sites).

Society of Civil Engineers ASCE (1949) recommended that the base surge should be selected so that $N_{u}$ is greater than $N$, but that there should not be more than three or four events above the threshold in any one year. The CETMEF (2013) in
France recommended a range of two to eight events per year. As it can be concluded from the table presented in Fig. 1, this criterion was respected for the majority of sites except Boulogne, Port Tudy, St-Nazaire, and St-Gildas. The base 

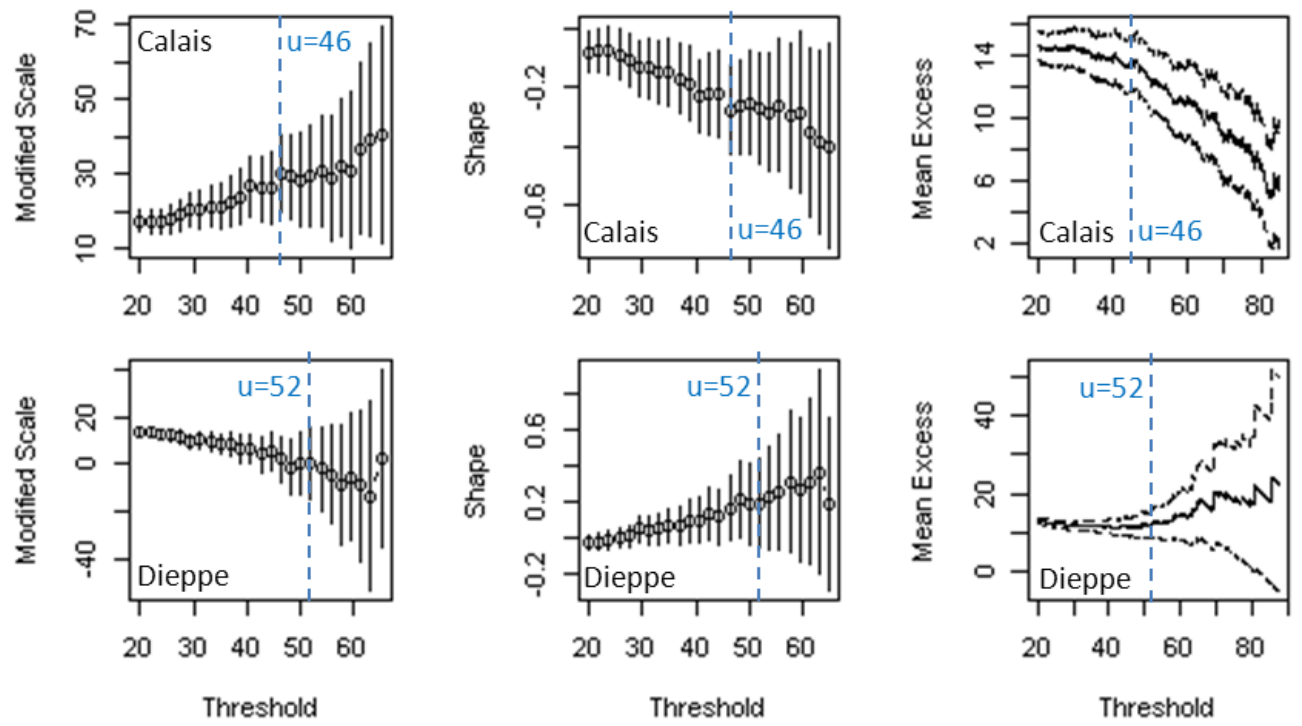

Figure 3. Estimation of $u$ (threshold $-\mathrm{cm}$ ): the GPD modified scale and shape parameters and mean excess life plot with $95 \%$ confidence intervals (Calais and Dieppe sites).

surges used in the present study are similar to those recommended by the UK Flood Studies Report (Natural Environment Research Council, 1975). This range of values of $N_{u}$ was recommended by the US Geological Survey (Dalrymple, 1960), Tavares and da Silva (1983) and Jayasuriya and Mein (1985) as well.

\subsection{Screening for outliers}

Working with events in an extreme environmental conditions context requires caution about the input data. The French Atlantic sea level data sets were never screened for the numerical detection of outliers. The GBT was applied on series of log-transformed extreme storm surges for all stations within the selected subset. The GBT is based on the difference of the mean of the sample and the most extreme data considering the standard deviation (Grubbs and Beck, 1972). Under the hypothesis that the logarithm of the sample is normally distributed, the GBT, with a significance level equal to $5 \%$, highlights the extreme events with very low probabilities of occurrence. The table presented in Fig. 1 shows, for each site, the GBT statistic for the MA, $r$-LOS, and POT data sets. Sites for which the GB-statistic exceeded the onesided critical point for GBT have experienced outliers (written with bold characters). Seven potential outliers at seven different sites (Boulogne, Dieppe, Le Havre, Cherbourg, Le Conquet, Brest, and La Rochelle) were identified in the case of AM data sets. Three additional outliers at three different sites (Roscoff, St-Nazaire, and Bayonne) were detected when the $r$-LOS approach is used. Four other potential outliers at four additional sites (Dunkerque, Olonne, Port Bloc, and St-Jean) were detected by the GBT applied on the POT series. The analysis of climatic conditions on the day the out- lier took place shows that there is no evidence of unrealistic storm surges (storms of 1953, 1969, 1979, 1987, 1999, and 2010), all the detected outliers have been considered as credible and as a result, we kept all of them in the present study.

\subsection{Randomness, stationarity and homogeneity tests}

The record length was the first criterion to select the stations. As a second prerequisite for frequency analysis, all the time series of extreme storm surges (AM, POT, and $r$-LOS) must be homogeneous, stationary and independent. Table 1 shows the KT (for stationarity), the WWT (for independency) and the Wilcoxen (for homogeneity) statistics for AM, $r$-LOS, and POT data sets. Stations that failed these tests at significance levels of $5 \%$ are highlighted in the Table 1 (the corresponding $p$ values are italicised). Bayonne station failed the KT with a $p$ value equal to 0.029 , showing a possible trend in the AM data set. Dunkerque, Boulogne, and Bayonne stations failed the KT and WT with the $r$-LOS peaks. For the same type of data $(r$-LOS), the Cherbourg station failed the KT $(p$ value $=0.024)$. On the other hand, Bayonne station failed the KT and the WT with the POT data set. For all the approaches, only Port-Bloc station failed the WWT (for independency) when using the $r$-LOS data.

Another widely used non-parametric method of nonstationarity detection, the Spearman's rho test, has been also carried out on the $r$-LOS series that failed the Kendall test. The results (not presented in the present paper) confirm the presence of a statistically significant trend or cycle at the $5 \%$ significance level for Dunkerque, Cherbourg, and Bayonne sites. The consistency and stationarity of the stochastic characteristics of the surge time series at one or more stations may be influenced by many factors, from different observation 
Table 1. Stationarity, independence and homogeneity tests ( $p$ value).

\begin{tabular}{|c|c|c|c|c|c|c|c|c|c|}
\hline \multirow[t]{2}{*}{ Sites } & \multicolumn{3}{|c|}{ KT (stationarity) } & \multicolumn{3}{|c|}{ WWT (independence) } & \multicolumn{3}{|c|}{ WT (homogeneity) } \\
\hline & MA & $r$-LOS & POT & MA & $r$-LOS & POT & MA & $r$-LOS & POT \\
\hline 1. Dunkerque & 0.541 & 0.029 & 0.279 & 0.176 & 0.195 & 0.372 & 0.443 & 0.030 & 0.551 \\
\hline 2. Calais & 0.820 & 0.851 & 0.887 & 0.766 & 0.121 & 0.319 & 0.517 & 0.593 & 0.726 \\
\hline 3. Boulogne & 0.127 & 0.009 & 0.520 & 0.920 & 0.124 & 0.094 & 0.105 & 0.001 & 0.499 \\
\hline 4. Dieppe & 0.151 & 0.154 & 0.552 & 0.790 & 0.078 & 0.818 & 0.369 & 0.679 & 0.929 \\
\hline 5. Le Havre & 0.913 & 0.609 & 0.612 & 0.847 & 0.062 & 0.284 & 0.380 & 0.217 & 0.580 \\
\hline 6. Cherbourg & 0.079 & 0.024 & 0.171 & 0.612 & 0.808 & 0.081 & 0.443 & 0.126 & 0.229 \\
\hline 7. St-Malo* & - & - & - & - & - & - & - & - & - \\
\hline 8. Roscoff & 0.791 & 0.666 & 0.488 & 0.984 & 0.709 & 0.529 & 0.954 & 0.772 & 0.422 \\
\hline 9. Le Conquet & 0.788 & 0.604 & 0.857 & 0.186 & 0.639 & 0.693 & 0.583 & 0.950 & 0.459 \\
\hline 10. Brest & 0.909 & 0.242 & 0.347 & 0.476 & 0.200 & 0.124 & 0.726 & 0.613 & 0.222 \\
\hline 11. Concarneau* & - & - & - & - & - & - & - & - & - \\
\hline 12. Port Tudy & 0.797 & 0.091 & 0.288 & 0.549 & 0.588 & 0.846 & 0.982 & 0.221 & 0.23 \\
\hline 13. Le Crouesty* & - & - & - & - & - & - & - & - & - \\
\hline 14. St-Nazaire & 0.766 & 0.397 & 0.722 & 0.209 & 0.938 & 0.134 & 0.242 & 0.281 & 0.719 \\
\hline 15. St-Gildas & 0.950 & 0.984 & 0.868 & 0.274 & 0.249 & 0.424 & 0.302 & 0.132 & 0.908 \\
\hline 16. Olonne & 0.461 & 0.444 & 0.522 & 0.864 & 0.155 & 0.698 & 0.898 & 0.749 & 0.163 \\
\hline 17. La Rochelle & 0.826 & 0.182 & 0.932 & 0.174 & 0.834 & 0.835 & 0.902 & 0.132 & 0.801 \\
\hline 18. Port Bloc & 0.599 & 0.513 & 0.204 & 0.511 & 0.025 & 0.397 & 0.549 & 0.686 & 0.200 \\
\hline 19. Arcachon* & - & - & - & - & - & - & - & - & - \\
\hline 20. Bayonne & 0.029 & 0.001 & 0.005 & 0.702 & 0.079 & 0.823 & 0.079 & 0.035 & 0.002 \\
\hline 21. St-Jean & 0.975 & 0.710 & 0.490 & 0.678 & 0.481 & 0.863 & 0.845 & 0.693 & 0.381 \\
\hline
\end{tabular}

* Data series are very short.

techniques to climate change. Because storm surges can exhibit marked periodic behavior on both annual and diurnal timescales, naturally their extremes do as well. However, such cycles in extremes have not received much attention, as the AM technique does not require their explicit modeling. The annual periodicity (seasonality) in extreme storm surges is more present and visible in the $r$-LOS data sets than in the POT ones, especially for large values of $r$. However, as the Kendall and Spearman tests applied to the POT series did not show any statistically significant non-stationarity for all the stations, more intensive and comprehensive study is needed to foresee why these tests exhibited evidence of autocorrelations, trends or cycles in some $r$-LOS time series. The Dunkerque, Boulogne, Cherbourg, and Bayonne sites were then removed from the analysis.

\section{Results and discussion}

In this section we report the results of the AM, $r$-LOS and POT methods of extreme storm surge analysis applied to the French Atlantic storm surges data extracted, treated and presented in the last section. There are different ways to compare these statistical approaches: (i) examination of each method's uncertainty degree; (ii) comparative study based on return levels; (iii) comparative study based on adequacy criteria and tests; and (iv) visual examination based on diagnostic plots.

\subsection{Uncertainty degree}

It is possible to examine the uncertainty degrees of each method. As stated earlier, optimum values of $r$ and $u$ were estimated for each site. It is interesting to note that a model predicts the future return values well only if it produces return level estimates that fit inside the confidence interval. The $1 / p$ return levels $\hat{z}_{p}$ were calculated using Eq. (2). A degree of uncertainty in the estimates of a return level is closely related to that of the model parameters. The variance of our return level estimates was calculated using the delta method and an asymptotic approximation to the normal distribution as follows:

$\operatorname{var}\left(\hat{z}_{p}\right)=\nabla z_{p}^{t} \mathbf{V} \nabla z_{p}$,

where $\nabla z_{p}$ is the vector of first derivatives of $z_{p}$ and $\mathbf{V}$ is the variance-covariance matrix of the estimated parameters $(\mu, \sigma, \xi)$.

$$
\begin{aligned}
& \nabla z_{p}=\left\langle\frac{\partial z_{p}}{\partial \mu}, \frac{\partial z_{p}}{\partial \sigma}, \frac{\partial z_{p}}{\partial \xi}\right\rangle=\left\langle 1,-\xi^{-1}\left(1-y_{p}^{-\xi}\right),\right. \\
& \left.\sigma \xi^{-2}\left(1-y_{p}^{-\xi}\right)-\sigma \xi^{-1} y_{p}^{-\xi} \log \left(y_{p}\right)\right\rangle .
\end{aligned}
$$

The variance-covariance matrix $\mathbf{V}$ was used to calculate standard errors and confidence intervals associated with the distribution parameters. Standard errors (and their corresponding $95 \%$ confidence intervals) of the GEV and GPD 
Table 2. MLEs and return levels with associated standard errors for GEV distribution using AM and $r$-LOS data (with optimum choice of $r$ ) and for GPD using POT data (with optimum choice of $u$ ).

\begin{tabular}{|c|c|c|c|c|c|c|c|c|c|}
\hline \multirow[t]{2}{*}{ Stations } & & \multicolumn{2}{|l|}{$\hat{\mu}$} & \multicolumn{2}{|l|}{$\hat{\sigma}$} & \multicolumn{2}{|l|}{$\hat{\xi}$} & \multirow[t]{2}{*}{$S_{100}(\mathrm{SE})$} & \multirow[t]{2}{*}{$S_{500}(\mathrm{SE})$} \\
\hline & & $\operatorname{MLE}(95 \% \mathrm{CI})$ & SE & $\operatorname{MLE}(95 \% \mathrm{CI})$ & SE & $\operatorname{MLE}(95 \% \mathrm{CI})$ & SE & & \\
\hline \multirow{3}{*}{ Dunkerque } & $\mathrm{AM}$ & $75.40(69.49: 81.32)$ & 3.02 & $16.18(12.07: 20.28)$ & 2.10 & $-0.175(-0.380: 0.030)$ & 0.105 & $126.51(52.18)$ & $136.67(80.06)$ \\
\hline & POT & - & - & $13.53(9.26: 17.80)$ & 2.18 & $-0.033(-0.272: 0.207)$ & 0.122 & $121.83(6.15)$ & $140.07(10.75)$ \\
\hline & $r$-LOS & \multicolumn{8}{|c|}{ Dunkerque station failed the KT $(p$ value $=0.029)$ and the WT $(p$ value $=0.030)$} \\
\hline \multirow{3}{*}{ Calais } & AM & $61.85(56.38: 67.33)$ & 2.79 & $16.53(12.57: 20.49)$ & 2.02 & $-0.425(-0.623:-0.226)$ & 0.101 & $95.25(22.82)$ & $97.98(29.06)$ \\
\hline & POT & - & - & $17.55(13.81: 21.30)$ & 1.91 & $-0.277(-0.424:-0.130)$ & 0.075 & $91.67(5.40)$ & $98.03(7.61)$ \\
\hline & $r$-LOS & $55.94(52.22: 59.66)$ & 1.90 & $15.72(13.11: 18.32)$ & 1.33 & $-0.323(-0.453:-0.193)$ & 0.070 & $93.57(13.79)$ & $98.04(18.79)$ \\
\hline \multirow{3}{*}{ Boulogne } & AM & $61.63(55.40: 67.85)$ & 3.17 & $12.80(8.11: 17.50)$ & 2.40 & $0.136(-0.162: 0.434)$ & 0.152 & $143.51(149.24)$ & $186.74(316.90)$ \\
\hline & POT & - & - & $10.90(7.98: 13.83)$ & 1.49 & $0.104(-0.090: 0.299)$ & 0.099 & $106.43(11.02)$ & $137.31(22.58)$ \\
\hline & $r$-LOS & \multicolumn{8}{|c|}{ Boulogne station failed the KT $(p$ value $=0.009)$ and the WT $(p$ value $=0.001)$} \\
\hline \multirow{3}{*}{ Dieppe } & $\mathrm{AM}$ & $58.42(53.61: 63.23)$ & 2.45 & $13.00(9.27: 16.72)$ & 1.90 & $0.168(-0.073: 0.409)$ & 0.123 & $148.70(98.35)$ & $200.95(217.07)$ \\
\hline & POT & - & - & $10.26(6.84: 13.67)$ & 1.74 & $0.186(-0.062: 0.433)$ & 0.126 & $126.64(10.40)$ & $171.86(23.49)$ \\
\hline & $r$-LOS & $50.22(47.64: 52.79)$ & 1.31 & $12.43(10.64: 14.22)$ & 0.91 & $0.018(-0.070: 0.106)$ & 0.045 & $109.85(17.97)$ & $131.97(33.35)$ \\
\hline \multirow{3}{*}{ Le Havre } & $\mathrm{AM}$ & $66.11(59.34: 72.88)$ & 3.45 & $19.94(15.45: 24.44)$ & 2.29 & $-0.089(-0.238: 0.059)$ & 0.076 & $141.35(89.44)$ & $161.23(148.72)$ \\
\hline & POT & - & - & $13.72(10.18: 17.26)$ & 1.81 & $0.090(-0.098: 0.278)$ & 0.096 & $128.31(11.82)$ & $164.3(23.8)$ \\
\hline & $r$-LOS & $53.66(50.35: 56.97)$ & 1.69 & $16.81(14.58: 19.03)$ & 1.13 & $-0.064(-0.147: 0.019)$ & 0.042 & $120.59(23.06)$ & $139.76(39.30)$ \\
\hline \multirow{3}{*}{ Cherbourg } & $\mathrm{AM}$ & $47.25(43.19: 51.31)$ & 2.07 & $11.66(9.00: 14.33)$ & 1.36 & $-0.152(-0.286:-0.019)$ & 0.068 & $85.80(26.77)$ & $94.06(41.90)$ \\
\hline & POT & - & - & $7.60(5.15: 10.04)$ & 1.25 & $0.046(-0.186: 0.277)$ & 0.118 & 80.94(4.91) & $96.6(9.4)$ \\
\hline & $r$-LOS & \multicolumn{6}{|c|}{ Cherbourg station failed the KT $(p$ value $=0.024)$} & & \\
\hline \multirow{3}{*}{ Roscoff } & $\mathrm{AM}$ & $48.01(44.58: 51.44)$ & 1.75 & $9.84(7.50: 12.18)$ & 1.20 & $-0.162(-0.343: 0.018)$ & 0.092 & $79.90(18.37)$ & $86.52(28.49)$ \\
\hline & POT & - & - & $9.88(7.58: 12.18)$ & 1.17 & $-0.099(-0.258: 0.060)$ & 0.081 & 73.53(3.77) & $82.85(6.20)$ \\
\hline & $r$-LOS & $38.63(37.16: 40.10)$ & 0.75 & $8.32(7.28: 9.37)$ & 0.53 & $-0.057(-0.162: 0.047)$ & 0.053 & $72.29(4.56)$ & $82.14(7.81)$ \\
\hline \multirow{3}{*}{ Le Conquet } & AM & $48.58(45.32: 51.83)$ & 1.66 & $9.62(7.25: 11.99)$ & 1.21 & $0.091(-0.084: 0.265)$ & 0.089 & $103.46(35.92)$ & $128.81(72.26)$ \\
\hline & POT & - & - & $8.17(6.33: 10.00)$ & 0.94 & $0.097(-0.062: 0.255)$ & 0.081 & $85.37(4.21)$ & $107.57(8.55)$ \\
\hline & $r$-LOS & $38.13(36.93: 39.33)$ & 0.61 & $7.88(7.02: 8.74)$ & 0.44 & $0.045(-0.033: 0.123)$ & 0.040 & $78.43(4.21)$ & $94.68(8.03)$ \\
\hline \multirow{3}{*}{ Brest } & $\mathrm{AM}$ & $51.88(48.23: 55.53)$ & 1.86 & $12.61(9.97: 15.24)$ & 1.34 & $0.047(-0.113: 0.206)$ & 0.081 & $116.57(38.70)$ & $142.75(74.12)$ \\
\hline & POT & - & - & $9.79(7.90: 11.68)$ & 0.97 & $0.070(-0.062: 0.202)$ & 0.067 & $95.25(3.82)$ & $118.32(7.53)$ \\
\hline & $r$-LOS & $43.17(41.74: 44.59)$ & 0.73 & $10.03(9.02: 11.03)$ & 0.51 & $0.004(-0.060: 0.069)$ & 0.033 & $94.56(7.64)$ & $113.19(14.30)$ \\
\hline & $\mathrm{AM}$ & $53.95(49.30: 58.61)$ & 2.37 & $10.93(7.31: 14.54)$ & 1.84 & $-0.412(-0.775:-0.048)$ & 0.186 & $76.50(16.33)$ & $78.44(20.95)$ \\
\hline Port Tudy & POT & - & - & $13.43(10.23: 16.63)$ & 1.63 & $-0.218(-0.388:-0.048)$ & 0.087 & $74.04(5.76)$ & $80.73(8.52)$ \\
\hline & $r$-LOS & $40.95(38.92: 42.97)$ & 1.03 & $9.77(8.34: 11.19)$ & 0.73 & $-0.113(-0.244: 0.018)$ & 0.067 & $75.96(7.25)$ & $84.52(11.76)$ \\
\hline & $\mathrm{AM}$ & $68.49(63.07: 73.91)$ & 2.76 & $11.63(7.60: 15.66)$ & 2.06 & $-0.078(-0.443: 0.288)$ & 0.186 & $113.46(55.48)$ & $125.78(93.13)$ \\
\hline St-Nazaire & POT & - & - & $17.20(13.69: 20.71)$ & 1.79 & $-0.156(-0.294:-0.019)$ & 0.070 & $96.46(8.85)$ & $108.37(13.81)$ \\
\hline & $r$-LOS & $46.97(44.93: 49.02)$ & 1.04 & $11.68(10.18: 13.18)$ & 0.76 & $-0.011(-0.134: 0.112)$ & 0.063 & $99.43(9.92)$ & $117.23(17.85)$ \\
\hline & $\mathrm{AM}$ & $56.67(51.60: 61.73)$ & 2.59 & $11.75(8.09: 15.41)$ & 1.87 & $-0.144(-0.461: 0.172)$ & 0.161 & $96.16(40.55)$ & $104.86(63.89)$ \\
\hline St-Gildas & POT & - & - & $13.47(10.26: 16.67)$ & 1.63 & $-0.087(-0.265: 0.091)$ & 0.091 & $86.07(8.57)$ & $99.59(14.27)$ \\
\hline & $r$-LOS & $47.15(44.07: 50.23)$ & 1.57 & $12.81(10.66: 14.95)$ & 1.09 & $-0.176(-0.312:-0.039)$ & 0.070 & $87.55(14.14)$ & $95.57(21.67)$ \\
\hline & $\mathrm{AM}$ & $56.12(50.18: 62.06)$ & 3.03 & $11.92(7.43: 16.42)$ & 2.29 & $-0.179(-0.624: 0.267)$ & 0.227 & $93.52(48.50)$ & $100.86(74.06)$ \\
\hline Olonne & POT & - & - & $11.90(7.77: 16.03)$ & 2.11 & $-0.13(-0.38: 0.12)$ & 0.127 & $86.26(9.34)$ & 95.77(14.93) \\
\hline & $r$-LOS & $42.67(39.89: 45.45)$ & 1.42 & $11.94(9.99: 13.89)$ & 1.00 & $-0.125(-0.267: 0.017)$ & 0.072 & $84.45(13.24)$ & $94.27(21.26)$ \\
\hline & $\mathrm{AM}$ & $48.75(37.77: 59.73)$ & 5.60 & $20.28(12.41: 28.15)$ & 4.01 & $0.048(-0.252: 0.348)$ & 0.153 & $153.20(350.90)$ & $195.67(673.90)$ \\
\hline La Rochelle & POT & - & - & $9.18(5.51: 12.85)$ & 1.87 & $0.238(-0.070: 0.546)$ & 0.157 & $116.86(26.04)$ & $170.76(62.80)$ \\
\hline & $r$-LOS & $44.40(39.86: 48.93)$ & 2.31 & $13.75(10.54: 16.95)$ & 1.63 & $0.045(-0.108: 0.199)$ & 0.078 & $114.67(60.20)$ & $142.99(115.15)$ \\
\hline & AM & $50.99(43.69: 58.29)$ & 3.72 & $14.59(9.38: 19.80)$ & 2.66 & $-0.299(-0.623: 0.025)$ & 0.165 & $87.43(55.71)$ & $92.14(77.21)$ \\
\hline Port Bloc & POT & - & - & $11.48(7.13: 15.83)$ & 2.22 & $-0.098(-0.386: 0.191)$ & 0.147 & $84.56(11.89)$ & $95.46(19.60)$ \\
\hline & $r$-LOS & Port Bloc station fail & $d$ the $V$ & $\Gamma(p$ value $=0.025)$ & & & & & \\
\hline & $\mathrm{AM}$ & Bayonne station faile & the $\mathrm{K}$ & value $=0.029)$ & & & & & \\
\hline Bayonne & POT & Bayonne station faile & the $\mathrm{K}$ & value $=0.005)$ and the & NT $(p$ & $\mathrm{ue}=0.002)$ & & & \\
\hline & $r$-LOS & Bayonne station faile & the $\mathrm{K}$ & value $=0.001)$ and the & WT $(p$ & $\mathrm{e}=0.035)$ & & & \\
\hline & $\mathrm{AM}$ & $35.98(33.14: 38.82)$ & 1.45 & $7.42(5.37: 9.47)$ & 1.05 & $-0.226(-0.477: 0.026)$ & 0.128 & $57.21(10.29)$ & $60.76(15.11)$ \\
\hline St-Jean & POT & - & - & $9.02(7.12: 10.92)$ & 0.97 & $-0.233(-0.362:-0.105)$ & 0.066 & $52.45(2.57)$ & $56.58(3.76)$ \\
\hline & $r$-LOS & $33.42(31.67: 35.18)$ & 0.90 & $6.53(5.29: 7.77)$ & 0.63 & $-0.150(-0.315: 0.015)$ & 0.084 & $55.10(4.93)$ & $59.79(7.72)$ \\
\hline
\end{tabular}

distribution parameters and of 100, 500, and 1000-year return levels were estimated and examined for each method and each site (Table 2). Stations that failed one or several tests at levels up to $5 \%$ were eliminated for the present analysis (5 stations in total). The standard errors of $\hat{\mu}$ and $\hat{\sigma}$ parameters are relatively small compared to their maximum 

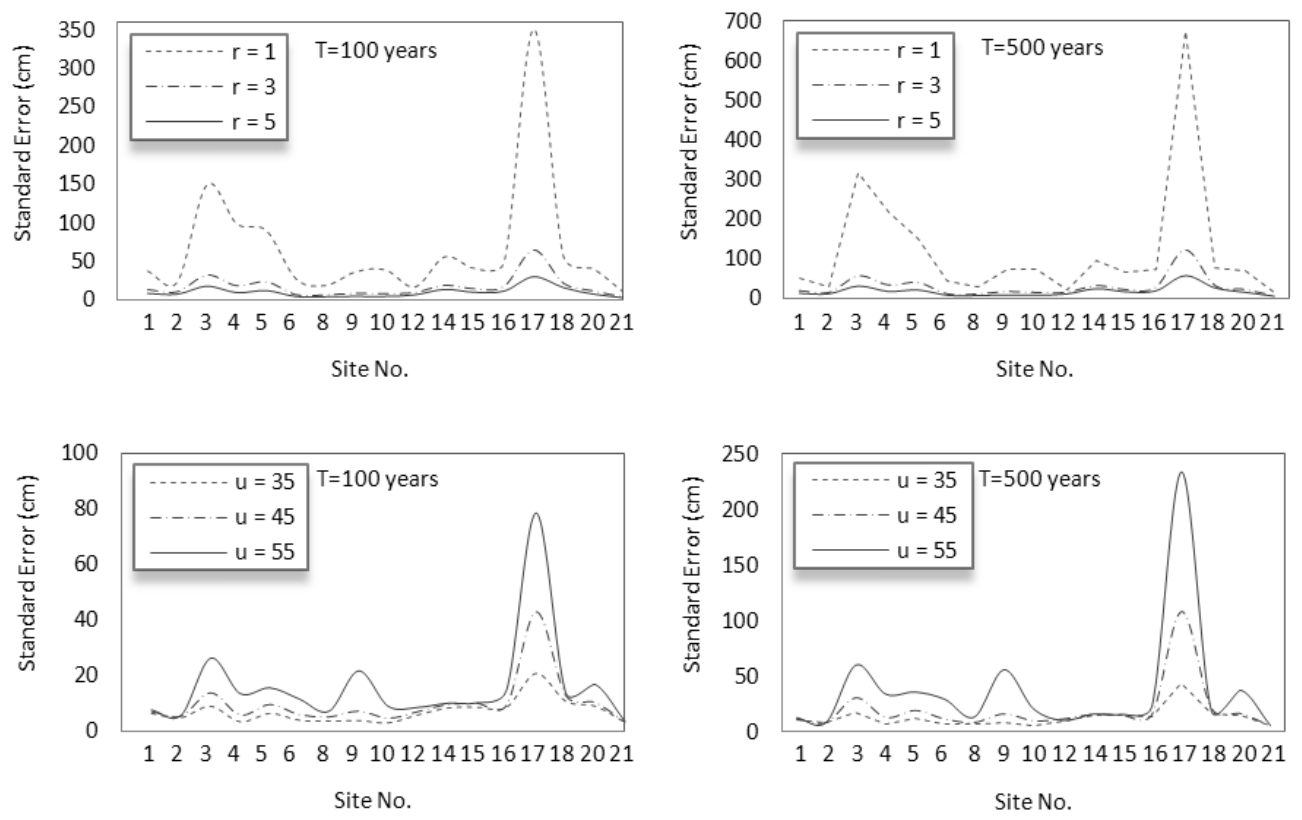

Figure 4. The standard error associated with 100-year (left) and 500-year (right) surges versus the value of $r$ (the $r$-largest observations) and $u$ (threshold). $T$ is the return period.

likelihood estimates (MLE). The results given in Table 2 indicate that a systematic reduction, compared to the AM and POT methods, in the uncertainty on the parameters estimation when using $r$-LOS approach (more confidence to parameters estimates). Indeed, compared to its MLE, the standard errors of the $\hat{\mu}$ parameter estimated with $r$-LOS time series are systematically smaller than those estimated with AM data sets. It can also be seen that the standard error of the $\hat{\sigma}$ parameter is systematically smaller than those estimated with POT and AM ones. Although the parameter uncertainty is often reduced when additional data is used, several stations show otherwise. This is the case for the Calais, Le Havre, Brest, Port Tudy, St-Nazaire, St-Gildas, and St-Jean stations where the POT approach results in more data than the $r$ LOS method without reducing the standard error. It can be concluded that additional information is a necessary condition for lowering the uncertainty and providing an improved model fit to the data. However, this does not imply that having more data will improve the model fit as more data will invalidate the asymptotic assumption. Also, contrarily to the POT method, when using the $r$-LOS approach, a relatively large number (depending on the value of $r$ ) of additional observations become available and it is subjective to say which of the available data is in fact extreme and which is not. In other words, the statistical gain will be better if we use fewer additional values which are really extreme (the case of the POT method with a fairly high threshold for example) instead of many more values that contain multiple observations that are not really extreme, as in the case of $r$-LOS time series for high values of $r$.
It can also be seen that standard errors of 50, 100, and 500year return levels decrease significantly, compared to the AM approach, for all the sites when using the $r$-LOS and the POT methods. This decrease in return levels is more noticeable with the POT method than for the $r$-LOS method. The use of the POT and the $r$-LOS methods leads to tighter confidence intervals as we are more certain about the theoretical return level and habitually the decrease in return levels is caused by lighter tails of distributions and smaller shape parameter given for the $r$-LOS and POT data sets. This allows us to conclude that there is a decreased probability of extreme events in the right tail of the distribution when compared to the fit given by the AM model.

The effect of considering more than a single value per year is also illustrated by Fig. 4, in which the standard errors corresponding to both the $r$-LOS and POT estimates of 100 and 500 -year storm surges are displayed. It can be seen that the standard errors are reduced by 3-11 times as $r$ increases from 1 to 5 , and by $1-8$ times as the threshold $u$ decreases from 55 to $35 \mathrm{~cm}$. It is also noteworthy that these differences in standard errors (when $r$ increases and/or $u$ decreases), become increasingly important as the size of the data sets decreases. It is undoubtedly an advantage of using the $r$-LOS and POT approaches instead of the AM method only when the data set size is relatively small.

\subsection{Return levels}

Table 2 exhibits the evidence that the GEV and GP distributions are heavy tailed (positive shape parameter $\xi$ ) when the data set is characterized by the presence of an outlier (e.g., 

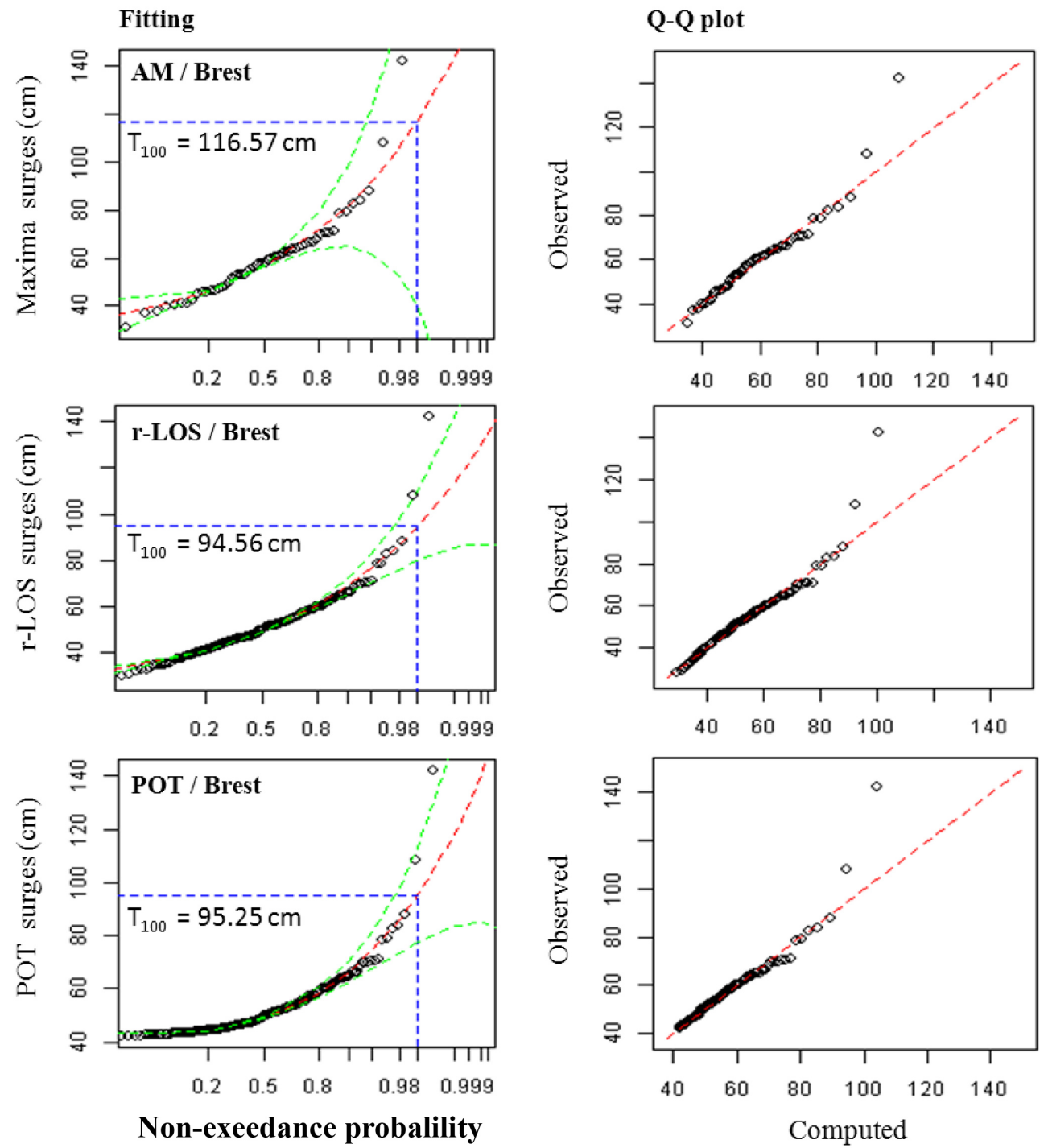

Figure 5. Visual inspection - example of a distribution fit (and Q-Q plot) for Brest station (with outlier) using AM (annual maxima), $r$ LOS ( $r$-largest order statistics) and POT (peaks over threshold) methods. The $95 \%$ lines correspond to confidence intervals. The $T_{100}$ is the 100 -years return period.

Dieppe, Brest, La Rochelle). However, the $\xi$ settings are not high enough for the theoretical curves to achieve these outliers. None of the three approaches has allowed an acceptable closeness of fit in the upper tail of the distribution function in the presence of outliers (Fig. 5). It can be seen that the AM method has given the largest return levels and that the point process (POT and $r$-LOS) methods result in lower return values. This increase is more noticeable when the $r$-LOS approach is used, especially in the presence of an outlier. On the other hand, empirical probabilities of observations without outliers (Calais, Roscoff, Port Tudy, St-Nazaire, StGildas, Olonne, St-Jean) are well fitted by the distribution functions. Return levels at 100 and 500 years are generally higher when the AM method is used but they are of the same order of magnitude when POT and $r$-LOS approaches are used. Finally, the negative shape parameter values (bounded distributions) should be used with caution because the $95 \%$ confidence interval often extends well above zero, so that the strength of evidence from the data for a bounded distribution is not strong.

\subsection{Adequacy criteria and tests}

As was mentioned in Sect. 2.3, a variety of adequacy criteria and tests were applied to decide which model best represents the extreme surge data sets. The results of these criteria and tests are presented in Table 3. The results of the AndersonDarling statistics indicated with bold letters ( $r$-LOS and POT approaches applied to Roscoff station) are the ones that are rejected with a $5 \%$ of confidence level. The Kolmogorov- 
Table 3. Adequacy criteria and test using AM, $r$-LOS and POT data sets (with optimum choice of $r$ and $u$ ).

\begin{tabular}{|c|c|c|c|c|c|c|}
\hline Stations & & Bias & RMSE & $\chi^{2}$ & $\begin{array}{l}\mathrm{KS} \\
(D)\end{array}$ & $\begin{array}{l}\mathrm{AD} \\
\left(A^{2}\right)\end{array}$ \\
\hline \multirow{3}{*}{ Dunkerque } & $\mathrm{AM}$ & 0.998 & 22.588 & 0.07 & 0.896 & 0.610 \\
\hline & $r$-LOS & \multicolumn{5}{|c|}{$\begin{array}{l}\text { Dunkerque station failed the KT } \\
\text { and the WT at the level } 5 \%\end{array}$} \\
\hline & POT & 0.996 & 17.39 & 1.00 & 0.837 & 0.668 \\
\hline \multirow{3}{*}{ Calais } & $\mathrm{AM}$ & 1.004 & 21.609 & 0.90 & 0.785 & 0.725 \\
\hline & $r$-LOS & 1.001 & 21.855 & 1.00 & 0.971 & 0.596 \\
\hline & POT & 0.999 & 15.229 & 1.00 & 0.990 & 0.791 \\
\hline \multirow{3}{*}{ Boulogne } & $\mathrm{AM}$ & 0.980 & 23.349 & 0.85 & 0.955 & 0.587 \\
\hline & $r$-LOS & \multicolumn{5}{|c|}{ Boulogne station failed the KT and the WT } \\
\hline & POT & 0.993 & 18.349 & 0.99 & 0.912 & 0.258 \\
\hline \multirow{3}{*}{ Dieppe } & $\mathrm{AM}$ & 0.983 & 24.789 & 0.46 & 0.996 & 0.156 \\
\hline & $r-\mathrm{LOS}$ & 0.999 & 21.876 & 0.47 & 0.622 & 0.962 \\
\hline & POT & 0.989 & 16.956 & 0.77 & 0.976 & 0.841 \\
\hline \multirow{3}{*}{ Le Havre } & $\mathrm{AM}$ & 0.999 & 30.228 & 0.89 & 0.366 & 0.996 \\
\hline & $r$-LOS & 1.002 & 28.608 & 0.99 & 0.269 & 1.000 \\
\hline & POT & 0.994 & 22.067 & 1.00 & 0.774 & 0.936 \\
\hline \multirow{3}{*}{ Cherbourg } & $\mathrm{AM}$ & 1.002 & 14.848 & 0.86 & 0.819 & 0.962 \\
\hline & $r-\mathrm{LOS}$ & \multicolumn{5}{|c|}{ Cherbourg station failed the KT } \\
\hline & POT & 0.995 & 10.652 & 1.00 & 0.905 & 0.383 \\
\hline \multirow{3}{*}{ Roscoff } & AM & 0.999 & 14.379 & 0.98 & 0.955 & 0.452 \\
\hline & $r-\mathrm{LOS}$ & 0.998 & 14.235 & 1.00 & 0.997 & 0.014 \\
\hline & POT & 0.997 & 11.782 & 1.00 & 0.998 & 0.042 \\
\hline \multirow{3}{*}{ Le Conquet } & $\mathrm{AM}$ & 0.990 & 20.691 & 0.46 & 0.814 & 0.762 \\
\hline & $r$-LOS & 0.998 & 15.976 & 0.95 & 0.999 & 0.238 \\
\hline & POT & 0.995 & 14.224 & 0.86 & 0.988 & 0.059 \\
\hline \multirow{3}{*}{ Brest } & AM & 0.994 & 24.058 & 0.96 & 0.820 & 0.736 \\
\hline & $r$-LOS & 0.999 & 18.757 & 0.85 & 0.881 & 0.832 \\
\hline & POT & 0.996 & 15.904 & 0.62 & 0.916 & 0.255 \\
\hline \multirow{3}{*}{ Port Tudy } & $\mathrm{AM}$ & 1.002 & 13.705 & 0.98 & 0.472 & 0.958 \\
\hline & $r$-LOS & 0.998 & 14.020 & 1.00 & 0.986 & 0.505 \\
\hline & POT & 0.999 & 12.212 & 1.00 & 0.974 & 0.720 \\
\hline \multirow{3}{*}{ St-Nazaire } & $\mathrm{AM}$ & 0.994 & 16.825 & 0.61 & 0.930 & 0.549 \\
\hline & $r-\mathrm{LOS}$ & 0.997 & 20.782 & 1.00 & 0.946 & 0.186 \\
\hline & POT & 0.998 & 17.582 & 1.00 & 0.648 & 0.240 \\
\hline \multirow{3}{*}{ St-Gildas } & $\mathrm{AM}$ & 0.995 & 17.430 & 0.98 & 0.947 & 0.120 \\
\hline & $r$-LOS & 0.999 & 19.506 & 1.00 & 0.907 & 0.385 \\
\hline & POT & 0.997 & 15.984 & 1.00 & 0.645 & 0.569 \\
\hline \multirow{3}{*}{ Olonne } & $\mathrm{AM}$ & 0.995 & 19.070 & 0.92 & 0.618 & 0.767 \\
\hline & $r$-LOS & 0.998 & 19.675 & 1.00 & 0.955 & 0.374 \\
\hline & POT & 0.996 & 12.319 & 1.00 & 0.706 & 0.841 \\
\hline \multirow{3}{*}{ La Rochelle } & $\mathrm{AM}$ & 0.948 & 18.988 & 0.77 & 0.936 & 0.230 \\
\hline & $r$-LOS & 0.992 & 23.204 & 0.07 & 0.577 & 0.970 \\
\hline & POT & 0.982 & 15.762 & 0.26 & 0.971 & 0.149 \\
\hline \multirow{3}{*}{ Port Bloc } & $\mathrm{AM}$ & 1.001 & 19.083 & 0.99 & 0.801 & 0.452 \\
\hline & $r-\mathrm{LOS}$ & \multicolumn{5}{|c|}{ Port Bloc station failed the WWT } \\
\hline & POT & 0.996 & 12.973 & 1.00 & 0.792 & 0.150 \\
\hline \multirow{3}{*}{ Bayonne } & $\mathrm{AM}$ & Bayon & e station & ailed th & $\mathrm{KT}$ & \\
\hline & $r-\mathrm{LOS}$ & Bayon & e station & ailed th & $\mathrm{KT}$ and & he WT \\
\hline & POT & Bayon & e station & ailed th & $\mathrm{KT}$ and & he WT \\
\hline & $\mathrm{AM}$ & 0.998 & 10.479 & 0.99 & 0.834 & 0.304 \\
\hline St-Jean & $r$-LOS & 0.998 & 9.644 & 1.00 & 0.856 & 0.592 \\
\hline & POT & 0.998 & 8.601 & 1.00 & 0.511 & 0.641 \\
\hline
\end{tabular}

Smirnov (KS) and the Chi-2 statistics resulted in $p$ values that indicate that no model is rejected for all the sites. These statistics, also presented in Table 3, do not give additional and reliable information for the selection of the appropriate model. The Chi-2 $p$ values are systematically smaller with the AM method. These probabilities are higher than conventional criteria for statistical significance (1-5\%), so normally we would not reject the null hypothesis about the parent distribution of the sample (GEV for AM and $r$-LOS data sets and GPD for POT samples). As mentioned in Sect. 2.3, these Chi-2 test results have the shortcoming of being considered, by the scientific community, not very powerful with continuous distributions (the test result depends strongly on the choice of the classes far more than the values of the sample).

As was also stated in Sect. 2.3, the Bias and RMSE were computed for each approach at all the selected sites. It is seen that, for all the sites, the bias is very close to 1 for all of the methods. This means the overall performance is good but this does not give additional information for the selection of the appropriate model. The RMSE provides a better indication for this selection. It can be seen that the RMSE of the estimates given by the AM and $r$-LOS methods are systematically higher than those given by POT. For the sake of consistent comparison, in addition to these adequacy criteria and tests we visually inspected, for each method and each site, diagnostic plots (fitting and Q-Q plots) illustrating the quality of the fit between the GEV distribution (for the AM and $r$-LOS methods) or the GP (for the POT method) and the observed probabilities. Figure 5 shows an example of a distribution fit; the example was selected because the station (Brest) is characterized by the presence of an outlier.

The visual inspection of diagnostic plots (Figs. 5 and 6) exhibits that the confidence intervals are tighter when point process (POT and $r$-LOS) methods are used. On the one hand this promotes these methods, but on the other hand the observations which are considered as outliers do not fit within these tighter confidence intervals. This is the case for Brest and several other stations. It is also interesting to note that in the presence of an outlier, the fitting at the right tail is not adequate for all the analyzed methods, with a slight advantage to the AM method which, as presented earlier in this section, gives higher return levels.

For data sets without outliers, the point process methods, especially the POT approach, provided an improved model fit to the observations, compared with the two other methods, and give good and appropriate fits at the upper tails. Figure 6 illustrates well this situation. Further visual analyses of the diagnostic plots have exhibited a difficulty in discriminating between the compared methods, especially when data sets are long enough and do not contain outliers. However, we can see that the POT method best fits the observations at the lower tails. 

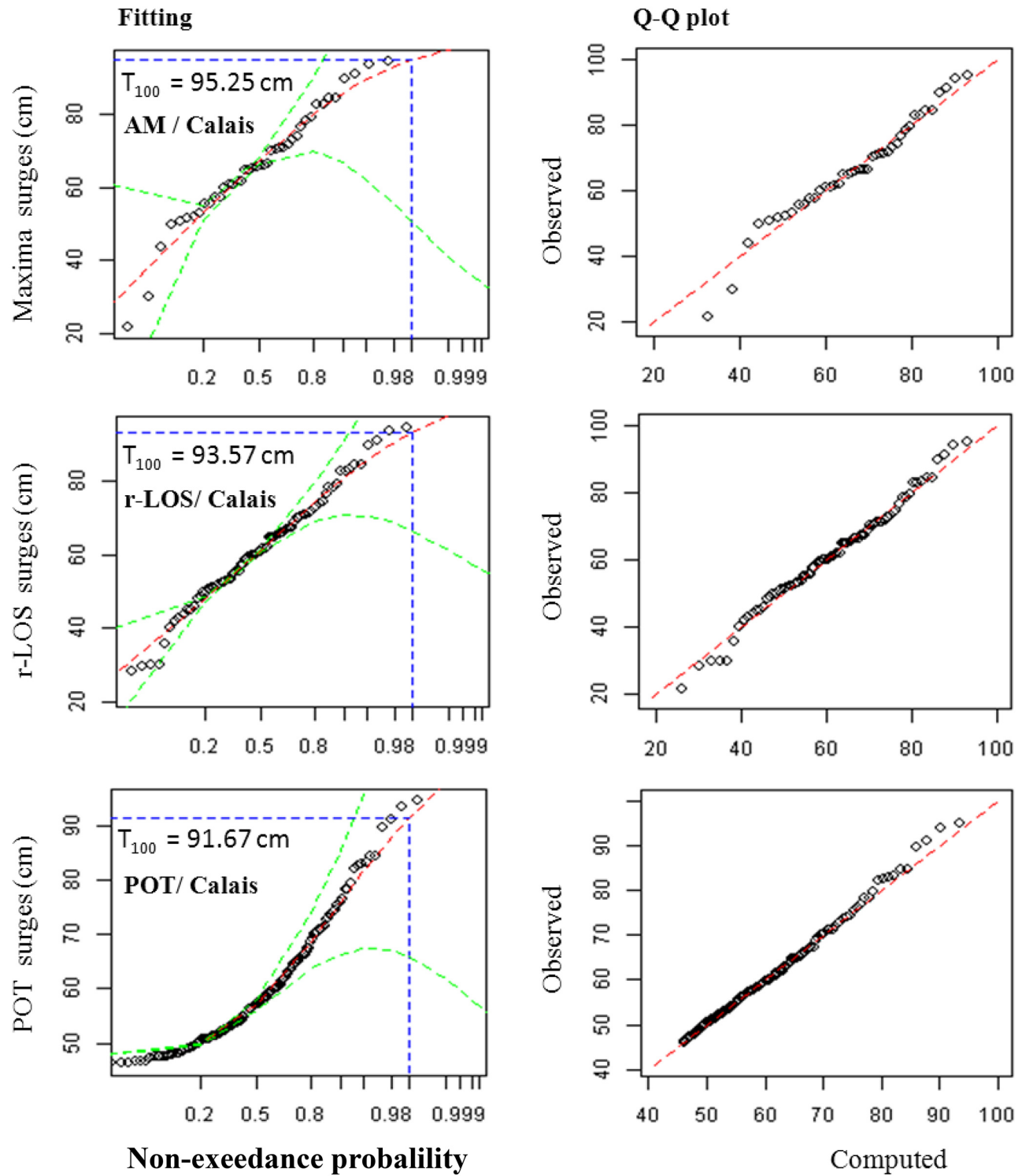

Figure 6. Visual inspection - example of a distribution fit (and Q-Q plot) for Calais station (without outlier) using AM (annual maxima), $r$-LOS ( $r$-largest order statistics) and POT (peaks-over-threshold) methods. The $95 \%$ lines correspond to confidence intervals. The $T_{100}$ is the 100 -year return period.

\subsection{Improving extreme surge frequency estimation}

When examining data sets containing outliers we are interested in asking the question: is the outlier of exceptional intensity? In order to answer this question we have to recognize if similar large or even larger historical events that may have occurred before the observation period, the "outlier" will look less exceptional. Therefore, it is important to get these nonsystematic data that will increase the representativeness of the outlier and enlarge the data set.

Historical data are generally imprecise and their inaccuracy should be properly accounted for in the analysis. However, even with substantial uncertainty in the data, the use of historical information is a viable mean to improve estimates of rare events related to extreme environmental conditions (e.g., Ouarda et al., 1998; Cœur and Lang, 2008; Pons, 2008; Hamdi, 2011; Payrastre et al., 2011). Several studies have emphasized the potential gain in estimation accuracy with the use of the historical information. A review of the literature on this subject has been made by Stedinger and Baker (1987) and Ouarda et al. (1998). 


\section{Concluding remarks}

Three frequency analysis methods, the annual maxima and the point process (peaks-over-threshold and the r-largest order statistics) were applied and compared. The principal objective of this study was to identify, for each site, the most reliable and adapted method. All the data sets were screened for outliers. Non-parametric tests for randomness, homogeneity and stationarity of time series were used. Stations that failed one or more of these tests were eliminated from the analysis. For the remaining stations, the shape and scale parameters stability plots, the mean excess residual life plot and the stability of the standard errors of return levels were used to select optimal thresholds and $r$ values for each station for the POT and $r$-LOS method, respectively. The comparison of methods was done from three angles: (i) the uncertainty degrees, (ii) the adequacy criteria and tests, and (iii) the visual inspection.

Adequacy criteria and tests have failed to discriminate between the methods, except for the RMSE criterion, which highlighted the POT method. This is largely due to the fact that the methods have given rise to different samples. This difference in samples is most notable between the AM method and the point process ones. In an extreme value context it is wiser to account for the error with which we make our inferences. As we predict surges further into the future, it is important to qualify our estimates with an appropriate degree of uncertainty.

The results of the comparison based on uncertainty degrees were more discriminant. Overall, adding the $r$-LOS and POT data to the model has reduced the standard error of the parameter estimates and the 100 and 500 years return levels compared to the AM method. This also provided an improved model fit to the observations when data sets do not contain outliers. However, this does not imply that having more data will improve the model, as more data might invalidate the asymptotic assumption. When more data is available it is more difficult to determine which of the available data is in fact extreme and which is not. Indeed, these point process methods provide an improved model fit to the observations but not the outlier if it exists.

The visual inspection of diagnostic plots has confirmed the numerical results based on uncertainty degrees. The fitting and Q-Q plots have shown larger confidence intervals when the AM method is used. It was also exhibited that in the presence of an outlier the fitting at the right tail is not adequate for all the analyzed methods, with a slight advantage to the AM method that gives systematically higher estimates of return levels. It is therefore advised to be rather prudent in selecting a frequency analysis method. It will be more safe to use the AM method when the sample size is sufficiently high, elsewhere the POT method must be used.
Acknowledgements. The authors are grateful to the SHOM (Service Hydrographique et Océanographique de la Marine). The authors gratefully acknowledge Xavier KERGADALLAN (CETMEF: Centre d'études techniques maritimes et fluviales) for his collaboration and for the scientific support he has given to this work.

Edited by: H. de Moel

Reviewed by: two anonymous referees

\section{References}

Alam, M. J. B. and Matin, A.: Study of plotting position formulae for Surma basin in Bangladesh, Journal of Civil Engineering (IEB), 33, 9-17, 2005.

An, Y. and Pandey, M. D.: The r-Largest Order Statistics Model for Extreme Wind Speed Estimation, J. Wind Eng. Ind. Aerod., 95, 165-182, 2007.

ASCE Hydrology Committee: Hydrology handbook: manuals of engineering practice \#28, ASCE, New York, 1949.

Ashkar, F. and Ouarda, T. B. M. J.: On some methods of fitting the generalized Pareto distribution, J Hydrol., 117, 117-141, 1996.

ASN (Nuclear Safety Authority): Protection des installations nucléaires de base contre les inondations externes, Guide no. 13, 40 pp., 2013 (in French).

Bardet, L. and Duluc, C.-M.: Apport et limites d'une analyse statistique régionale pour l'estimation de surcotes extrêmes en France, Congrès de la SHF, Paris, 1-2 février 2012 (in French).

Bardet, L., Duluc, C.-M., Rebour, V., and L'Her, J.: Regional frequency analysis of extreme storm surges along the French coast, Nat. Hazards Earth Syst. Sci., 11, 1627-1639, doi:10.5194/nhess-11-1627-2011, 2011.

Bernardara, P., Andreewsky, M., and Benoit, M.: Application of regional frequency analysis to the estimation of extreme storm surges, J. Geophys. Res., 116, C02008, doi:10.1029/2010JC006229, 2011.

Bernier, N. and Thompson, K. R.: Predicting the Frequency of Storm Surges and Extreme Sea Levels in the Northwest Atlantic, J. Geophys. Res., 111, C10009, doi:10.1029/2005JC003168, 2006.

Butler, A., Heffernan, J. E., Tawn, J. A., Flather, R. A., and Horsburgh, K. J.: Extreme value analysis of decadal variations in storm surge elevations, J. Marine Syst., 67, 189-200, 2007.

CETMEF: Analyse statistique des niveaux d'eau extrêmes - Environnements maritime et estuarien. CETMEF, France, Open File Rep. C 13.01, 180 pp., 2013 (in French).

Chow, V. T.: Frequency analysis of hydrologic data with special application to rainfall intensities, University of Illinois, Engineering Experiment Station. Bulletin, no. 414, 1953.

Chow, V. T., Maidment, D. R., and Mays, L. R.: Applied Hydrology, McGraw-Hill, New York, 1988.

Cœur, D. and Lang, M.: Use of documentary sources on past flood events for flood risk management and land planning, C. R. GEOSCI., 340, 644-650, 2008.

Coles, S.: An Introduction to Statistical Modeling of Extreme Values, Springer, Berlin, 2001.

Cunnane, C.: Unbiased Plotting Positions - A Review, J. Hydrol., 37, 205-222, 1978. 
Cunnane, C. and Singh, V. P. (Eds.): Review of statistical models for flood frequency estimation, in: Hydrologic Frequency Modeling, D. Reidel, Dordrecht, Netherlands, 49-95, 1987.

Dalrymple, T.: Flood Frequency Analyses, Manual of Hydrology: Part 3, Flood Flow Techniques, USGS Water Supply Paper, 1543-A, 51-77, 1960.

Fisher, R. A. and Tippett, L. H. C.: Limiting forms of the frequency distribution of the largest or smallest member of a sample, P. Camb. Philos. Soc., 24, 180-190, 1928.

Gringorten, I. I.: A plotting rule for extreme probability, J. Geophys. Res., 68, 813-814, 1963.

Grubbs, F. E. and Beck, G.: Extension of sample sizes and percentage points for significance tests of outlying observations, Technometrics, 14, 847-854, 1972.

Guedes Soares, G. and Scotto, M. G.: Application of the r Largest Order Statistics Model for Long-Term Predictions of Significant Wave Height, Coast. Eng., 51, 387-394, 2004

Hamdi, Y.: Frequency analysis of droughts using historical information - new approach for probability plotting position: deceedance probability, International Journal of Global Warming, 3, 203 218, 2011.

Irish, J. L., Resio, D. T., and Divoky, D.: Statistical properties of hurricane surge along a coast, J. Geophys. Res., 116, C10007, doi:10.1029/2010JC006626, 2011.

Jayasuriya, M. D. A. and Mein, R. G.: Frequency Analysis Using the Partial Series, in: Hydrology and Water Resources Symposium, Sydney, 14-16 May 1985, IEAust. Natl. Conf. Publ. No. 85/2, 81-85, 1985.

Jenkinson, A. F.: The frequency distribution of the annual maximum (or minimum) values of meteorological elements, Q. J. Roy. Meteor. Soc., 81, 158-171, 1955.

Makkonen, L.: Plotting Positions in Extreme Value Analysis, J. Appl. Meteorol. Clim., 45, 334-340, 2006.

Mann, H. B.: Nonparametric tests against trend, Econometrica, 3, 245-259, 1945.

Mattéi, J. M., Vial, E., Rebour, V., Liemersdorf, H., and Türschmann, M.: Generic Results and Conclusions of Reevaluating the Flooding in French and German Nuclear Power Plants, Eurosafe Forum, Paris, 23 pp., 2001.

Mauelshagen, F.: Flood Disasters and Political Culture at the German North Sea Coast: A Long-term Historical Perspective, Hist. Soc. Res., 32, 133-144, 2007.

Natural Environment Research Council: Flood Studies Report, Vol I-V, London, UK, 1975.

Northrop, P. J. and Jonathan, P.: Threshold modeling of spatially dependent non-stationary extremes with application to hurricaneinduced wave heights, Environmetrics, 22, 799-809, 2011.
Ouarda, T. B. M. J., Rasmussen, P. F., Bobée, B., and Bernier, J.: Utilisation de l'information historique en analyse hydrologique fréquentielle, Revue des sciences de l'eau/Journal of Water Science, 11, 41-49, 1998 (in French).

Payrastre, O., Gaume, E., and Andrieu, H.: Usefulness of historical information for flood frequency analyses: Developments based on a case study, Water Resour. Res., 47, W08511, doi:10.1029/2010WR009812, 2011.

Pickands, J. III: Statistical inference using extreme order statistics, Ann. Stat., 3, 119-131, doi:10.1214/aos/1176343003, 1975.

Pons, F.: Utilisation des données anciennes pour la connaissance des risques de submersions marines, Colloque SHF: Nouvelles approches sur les risques côtiers, Paris, 30-31 janvier 2008 (in French).

Rao, A. R. and Hamed, K. H.: Flood Frequency Analysis, CRC Press, Boca Raton, Florida, 2000.

Rao, A. R. and Hamed, K. H.: Flood Frequency Analysis, CRC Press, New York, 2001.

Smith, R. L.: Extreme value theory based on the $r$ largest annual events, J. Hydrol., 86, 27-43, 1986.

Stedinger, J. R.: Flood Frequency Analysis in the United States: Time to Update, J. Hydrol. Eng., 13, 199-204, 2008.

Stedinger, J. R. and Baker, V. R.: Surface water hydrology: Historical and paleoflood information, Rev. Geophys., 25, 119-124, 1987.

Steele, M. and Chaseling, J.: Powers of discrete goodness-of-fit test statistics for a uniform null against a selection of alternative distributions, Commun. Stat-Simul. C, 35, 1067-1075, 2006.

Stephens, M. A.: EDF Statistics for Goodness of Fit and Some Comparisons, J. Am. Stat. Assoc., 69, 730-737, 1974.

Tavares, L. V. and da Silva, J. E.: Partial Series Method Revisited, J. Hydrol., 64, 1-14, 1983.

Tawn, J. A.: An extreme value theory model for dependent observations, J. Hydrol., 101, 227-250, 1988.

Von Storch, H., Gönnert, G., and Meine, M.: Storm surges - An option for Hamburg, Germany, to mitigate expected future aggravation of risk, Environ. Sci. Policy, 11, 735-742, 2008.

Wald, A. and Wolfowitz, J.: An Exact Test for Randomness in the Non-Parametric Case Based on Serial Correlation, Ann. Math. Stat., 14, 378-388, 1943.

Weibull, W.: A statistical theory of strength of materials, in: Ingeniörsvetenskapsakademiens handlingar, Generalstabens litografiska anstalts förlag, 151, 1-45, 1939.

Wilcoxon, F.: Individual comparisons by ranking methods, Biometrics Bulletin, 1, 80-83, 1945. 